\title{
Evaluation of acute low back pain in women after treatment with interferential current
}

\author{
Andressa Serafim ${ }^{1}$, Jéssica Rabel ${ }^{1}$, Morgana Neves', Taciane Stein da Silva', \\ Gladson Ricardo Flor Bertolini' \\ 1 Universidade Estadual do Oeste do Paraná, Brazil
}

Serafim A, Rabel J, Neves M, Stein da Silva T, Ricardo Flor Bertolini G. Evaluation of acute low back pain in women after treatment with interferential current. J Pre-Clin Clin Res. 2019; 13(2): 57-60. doi: 10.26444/jpccr/109752

\begin{abstract}
Introduction and objectives. Low back pain has become one of the major public health problems worldwide. Treatment is by the use of analgesics and non-steroidal anti-inflammatory drugs, but it must be taken into account that these have side-effects. Therefore, non-pharmacological therapies may be beneficial in patients at greater risk of developing chronic pain and disability, aiming to decrease pain. The objective of this study was to assess the effect of the Interferential current in women with acute low back pain.

Materials and method. The study included female patients, aged 18 - 35 years, who had acute low back pain. The Visual Analogue Scale (VAS) of Pain and the Oswestry Disability Index (ODI) were used for evaluation. The patients received Interferential current in the bipolar form, the parameters were base current of $2 \mathrm{kHz}, \mathrm{AMF} 50 \mathrm{~Hz}$, which was performed for 20 minutes daily, for 3 non-consecutive days in the week, for 4 weeks, totaling 12 therapies.

Results. For evaluation of pain intensity, no difference was observed in the control group with a small effect size, but the treated group had a large effect size. For the ODI, comparison within the group showed no difference for the control group, but there was a decrease in the values for the treated group.

Conclusion. It was found that the Interferential current was effective in the reduction of acute low back pain and functional improvement.
\end{abstract}

\section{Key words}

pain management, musculoskeletal pain, acute pain, low back pain, transcutaneous electric nerve stimulation, electric stimulation therapy.

\section{INTRODUCTION}

Lumbar pain, or low back pain, has become one of the major public health problems in the Western world during the mid-20th century, and currently seems to be spreading throughout the world, with costs rising sharply. The prevalence, depending on the literature consulted, may reach $84 \%$, affecting all age groups. Non-specific low back pain is defined as low back pain not attributable to a recognized cause or specific disease (infection, tumour, osteoporosis, fracture, structural deformity, inflammatory disorder, root syndrome, or equine tail syndrome), is generally associated with sedentary occupations, smoking and obesity, with higher incidence in the low socio-economic classes [1-4]

Acute mechanical low back pain may originate from one or more structures of the spine, including ligaments, joints, intervertebral discs, musculature and paravertebral fascia, and spinal nerve roots. For treatment, there is the use of analgesics and non-steroidal anti-inflammatory drugs, muscle relaxants, and opioids, but it must be taken into account that these have side-effects. Therefore, nonpharmacological therapies may be beneficial in patients at greater risk of developing chronic pain and disability, aiming to decrease pain $[5,6]$.

The mechanisms of action of many treatments are unclear, considering both patient preference and evidence for pain control. Most people recover from acute low back pain, but

Addres for correspondence: Gladson Ricardo Flor Bertolini, Universidade Estadual do Oeste do Paraná, Brazil

E-mail: gladsonricardo@gmail.com

Received: 30 March 2019; accepted: 31 May 2019; first published: 30 May 2019
$10-33 \%$ may develop chronic symptoms, and it is considered that only exercise can be considered a preventive factor [1], then therapeutic treatment gains importance and may provide conditions for its development.

The interferential current is a medium frequency alternating current therapy with low-frequency amplitude modulation. It has been applied to pain relief and increased blood flow to the tissues. It penetrates deeper into the skin than lowfrequency equipment, such as TENS, with less discomfort [7-8]. However, its clinical impact is still controversial in low back pain, with few studies substantiating its efficacy, especially in relation to acute pain [10-11]. Thus, the objective of the present study was to evaluate its effect on young women with acute low back pain.

\section{MATERIALS AND METHOD}

The study was characterized as a randomized, cross-sectional clinical trial. The research was conducted at the Physical Rehabilitation Center of the State University of Western Paraná (Unioeste), in the city of Cascavel - Paraná - Brazil, with female volunteers who had acute, non-specific low back pain.

A total of 44 women were selected, with 2 dropouts and 1 who did not reach the pre-established criteria, totalling 41 volunteers (Fig. 1), aged 18 - 35 years. Inclusion criteria were: low back pain of less than 3 months, female gender, age between 18 - 35 years, did not use any analgesic medication or other forms of therapy during the research period. Women with previous lumbar spine surgery, the use of a pacemaker, 


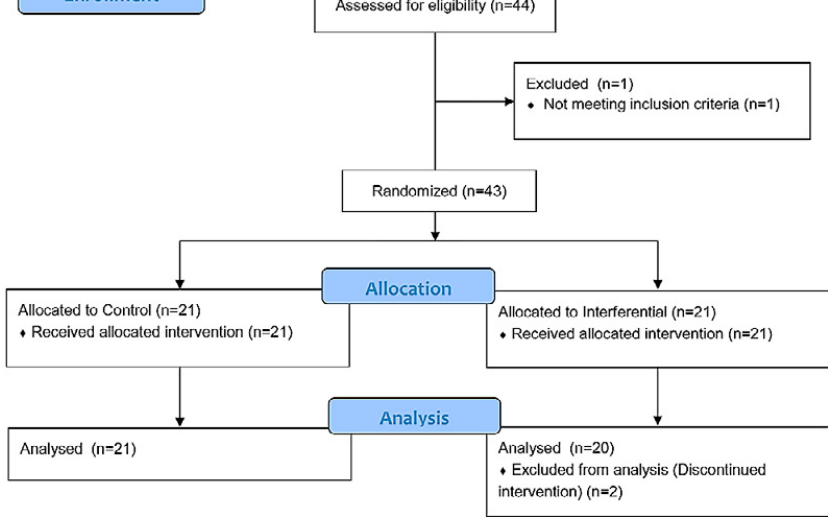

Figure 1. Study flow chart, according to Consort

presence of deep venous thrombosis, tuberculosis or tumours, were excluded from the study. The volunteers were divided into 2 groups: a control group $(n=21)$, in which the volunteers only performed the evaluations, without any type of therapy, only offered therapy at the end of the experiment period; and a group treated with interferential current $(n=20)$.

At the beginning of the study, each volunteer was informed about the intentions and procedures that would be performed during the research, as well as being questioned about their interest in participating in the study. Upon acceptance of the invitation, the participants signed an informed consent form. The study was aproved by the Research Ethics Committee of UNIOESTE (Opinion No. 2,858,177).

Electro Stimulation Protocol. In order to perform the therapy, the volunteers were placed in a ventral decubitus position on a stretcher with the lower back bare, to which $70 \%$ alcohol asepsis was applied with cotton wool. Two channels were used, with four rubber-silicon electrodes of $8 \mathrm{~cm}^{2}$, arranged longitudinally on the lumbar spine, attached with adhesive tape. Two electrodes were positioned in the T12 region and the other two in the L5 region; water-soluble gel was added to each electrode. The patients were then given Interferential current in the form, using Ibramed $^{\oplus}$ brand equipment. The treatment parameters were: base current of $2 \mathrm{kHz}$, AMF $50 \mathrm{~Hz}$, performed for 20 minutes daily for 3 non-consecutive days in the week for 4 weeks, a total of 12 therapies. The intensity was established according to the patient's sensitivity, and should be referred to as a noticeable and strong, but comfortable sensation.

Analyzed variables. During the first week, the volunteers were submitted to initial evaluation (EV1). Afterwards, separation was performed in the treated (Interferential) and control groups by means of an opaque envelope draw. At the end of the fourth week, they were again evaluated (EV2).

Pain assessment was performed using the Visual Analogue Pain Scale (VAS), which was explained by the researcher and the volunteer reported her pain in the last 24 hours, according to an illustrated scale numbered from 0 (no pain) to 10 (maximum pain) in both EV1 and EV2.

Evaluation of the impact of pain on the activities of daily living was calculated by the Oswestry Disability Index (ODI), which is an instrument for functional evaluation of the lumbar spine. The first question assesses the intensity of pain and the other nine, the effect of pain on daily activities, ranging from $0-5$. The score is classified as minimum disability (0-20\%), moderate disability (21-40\%), severe disability (41-60\%), invalid (61-80\%), and bed restricted [12].

Statistical analysis. For the sample size calculation, difference in the means of 1.0, standard deviation of 1.6, test power of $80 \%$ and the significance level of $5 \%$ was used, with a total of 22 people per group. The groups were presented with descriptive analysis, and the paired t-test (intra-group comparison) and non-paired t-test (comparison between groups) were used for statistical analysis of the VAS, and the Wilcoxon test used for the Oswestry Disability Index (intragroup) and MannWhytney (between groups). Significance level was set at 5\%, using the programme BioEstat 5.0. In addition, Cohen effect size calculation was performed.

\section{RESULTS}

In the pain intensity evaluation, no difference was observed in the control group with a small effect size, but was observed for the treated group, with a large effect size. When comparing the groups for the first evaluation, there was again no significant difference, but there was a moderate effect size, and in the final evaluation, there was a significant difference with a large effect size (Tab. 1).

Table 1. Mean and standard deviation values observed for VAS at different assessment moments (EV1 and EV2) for the two groups studied

\begin{tabular}{lcccc}
\hline & EV1 & EV2 & p-value & ES \\
\hline Control & $9 \pm 1.6$ & $2 \pm 1.6$ & 1860 & -0.19 \\
\hline Interferential & $9 \pm 2.1$ & $1 \pm 1.5$ & $<\mathbf{0 . 0 0 0 1}$ & -0.99 \\
\hline p-value & 0954 & $\mathbf{0 3 5 4}$ & & \\
\hline ES & -0.54 & 71 & &
\end{tabular}

ES - effect size.

For the ODI, comparison within each group showed no difference for the control group, but there was a decrease in the values for the treated group. There were no significant differences between the groups (Tab. 2).

Table 2. Presentation of values observed for ODI, in the median (below 1st and 3rd quartiles), at different moments of evaluation (EV1 and EV2) for the two groups studied

\begin{tabular}{lccc}
\hline & EV1 & EV2 & p-value \\
\hline Control & 8 & 9 & 1 \\
\hline Interferential & $3-15$ & $3-15$ & \\
\hline p-value & 5 & 0 & $\mathbf{0 0 7 6}$ \\
\hline
\end{tabular}

\section{DISCUSSION}

Most people obtain relief from acute low back pain fairly quickly, and only about $10-15 \%$ develop chronic symptoms. However, about $1 / 3$ of patients may not fully recover after 1 year. One of the major problems is recurrence, and physical exercise is an important preventive factor [1]. In the presented study, the aim was to evaluate whether the interferential 
current could lead to conditions of reduction of the pain for this type of patients, which could provide conditions for such activities as physical exercise. The result was that a significant reduction of pain was observed.

Two assessment tools were used in the study at two different moments, at the beginning of the treatment when it was intended to obtain the values of the visual analogue scale (VAS) and the Oswestry Disability Index (ODI) using the questionnaire. At the end of the treatment, a new evaluation was carried out using the same instruments in order to compare the 1st and 2 nd evaluations. This justified the single use of the current as a form of therapy, i.e, it was intended only to visualize possible analgesic effects of the current, without other forms of associated therapy.

Interferential current is used for various purposes, such as improvement in intestinal transit [13], dysphagia [14], increase in vascular flow [15] and muscle strengthening [16], but its main use is to produce analgesia [17]. However, there are conflicting results about its use, as presented by Kadi et al. [17] who used the interferential in the post-operative period of knee arthroplasty, which showed less use of paracetamol in only one of the evaluations, without advantages for other variables used in relation to pain. Similarly, Nazligul et al. [18] did not observe any advantages in applying the interferential on a protocol with exercises, cryotherapy and non-hormonal anti-inflammatory in patients with impact syndrome.

Concerning chronic lumbar pain, the reports indicate the advantages of interferential current, as in the study by Rajfur et al. [8], who compared TENS, high voltage, diadinamic and interferential, evaluating the intensity of pain, range of motion and spine function, and report that the use of interferential was effective in the treatment. AlbornozCabello et al. [10] observed reduction in the perception of pain and functional disability. Lara-Palomo et al.[19] also observed an improvement in pain, disability and quality of life when they used a massage technique with interferential current. Yet Franco et al.[20], observed that interferential may produce early reduction of pain when performed prior to Pilates exercises, but over time they did not observe advantages for pain intensity, pressure pain threshold, and disability [21]

Records of acute low back pain are scarce [11]. Hurley et al. [22] evaluated the use of interferential alone or in combination with spinal manipulation, reported that there were improvements in functional disability, analgesic medication consumption, pain, quality of life and participation in exercises, but without differences between groups. However, regardless of the studies cited in chronic or acute pain, the base frequency of the interferential current was $4,000 \mathrm{~Hz}[8$, $10,19-22]$. This variable is the target of studies since there is uncertainty about which current parameter degenerates the efficacy of the same $[23,24]$. In this way, the current study presents as a novelty the use of interferential current with base of 2,000 Hz, intended as an analgesia. This frequency is quoted as being less comfortable than higher frequencies [23]; however, for the volunteers in this study, it showed a reduction in pain intensity and disability, observed by intra and intergroup comparisons and corroborated by the effect sizes found. Also, the use of bipolar current was used despite the fact that this technique has less penetration [25] and less ability to produce changes in pain thresholds [26], due to the fact that there is no need for crossover and interference within the body, and is simpler and more practical to use in the clinical setting.
The use of VAS is widely accepted as an easy-to-use and reliable instrument for evaluating pain intensity and is widely used in the literature [10]. ODI is also widely used, but it allows a better evaluation of more severe pain in patients [12], which may have disrupted the comparison, especially among groups in the presented study, since both groups had already started with a score regarding minimum disability.

It is suggested that future studies should make comparisons with other variables, aimed at identifying the repercussions of this therapeutic modality, as well as its association with restorative physical exercises.

\section{CONCLUSION}

The study demonstrated that the use of Interferential current was effective in reducing acute low back pain in women, as well as improving aspects related to disability.

\section{REFERENCES}

1. Balagué F, Mannion AF, Pellisé F, Cedraschi C. Non-specific low back pain. Lancet. 2012; 379(9814): 482-91.

2. Clark S, Horton R. Low back pain: a major global challenge. Lancet. 2018; 391(10137): 2302.

3. Hill JC, Whitehurst DGT, Lewis M, Bryan S, Dunn KM, Foster NE, et al. Comparison of stratified primary care management for low back pain with current best practice (STarT Back): a randomised controlled trial. Lancet. 2011; 378(9802): 1560-71.

4. Taylor JB, Goode AP, George SZ, Cook CE. Incidence and risk factors for first-time incident low back pain: a systematic review and metaanalysis. Spine J. 2020; 14(10): 2299-319.

5. Golob AL, Wipf JE. Low back pain. Med Clin N Am. 2014; 98(3): 405-28.

6. Maher C, Underwood M, Buchbinder R. Non-specific low back pain. Lancet. 2017; 389(10070): 736-47.

7. Ariel E, Ratmansky M, Levkovitz Y, Goor-Aryeh I. Efficiency of tissue penetration by currents induced by three electrotherapeutic techniques: a comparative study using a novel deep-tissue measuring technique. Phys Ther. 2019; Epub ahead.

8. Rajfur J, Pasternok M, Rajfur K, Walewicz K, Fras B, Bolach B, et al. Efficacy of selected electrical therapies on chronic low back pain: a comparative clinical pilot study. Med Sci Monit. 2017; 23: 85-100.

9. Silva EPR da, Silva VR da, Bernardes AS, Matuzawa FM, Liebano RE. Study protocol of hypoalgesic effects of low frequency and burstmodulated alternating currents on healthy individuals. Pain Manag. 2018; 8(2): 71-7.

10. Albornoz-Cabello M, Espejo-Antúnez L, Heredia-Rizo AM, Domínguez-Maldonado G, Maya-Martín J. Effect of interferential current therapy on pain perception and disability level in subjects with chronic low back pain: a randomized controlled trial. Clin Rehabil. 2016; 31(2): 242-9.

11. Almeida CC de, Silva VZM da, Cipriano Júnior G, Liebano RE, Durigan JLQ. Transcutaneous electrical nerve stimulation and interferential current demonstrate similar effects in relieving acute and chronic pain: a systematic review with meta-analysis. Brazilian J Phys Ther. 2018; 22(5): 347-54.

12. Falavigna A, Teles AR, De Braga GL, Barazzetti DO, Lazzaretti L, Tregnago AC. Instrumentos de avaliação clínica e funcional em cirurgia da coluna vertebral. Coluna/Columna. 2011; 10(1): 62-7.

13. Zivkovic VD, Stankovic I, Dimitrijevic L, Kocic M, Colovic H, Vlajkovic $\mathrm{M}$, et al. Are interferential electrical stimulation and diaphragmatic breathing exercises beneficial in children with bladder and bowel disfunction? Urology. 2016; 102: 207-12.

14. Maeda K, Koga T, Akagi J. Interferential current sensory stimulation, through the neck skin, improves airway defense and oral nutrition intake in patients with dysphagia: a double-blind randomized controlled trial. Clin Interv Aging. 2017; 12: 1879-86.

15. Jin H-Y, Hwang T-Y, Cho S-H. Effect of electrical stimulation on blood flow velocity and vessel size. Open Med. 2017; 12: 5-11. 
16. Bellew JW, Beiswanger Z, Freeman E, Gaerte C, Trafton J. Interferential and burst-modulated biphasic pulsed currents yield greater muscular force than Russian current. Physiother Theory Pract. 2012; 28(5): 384-90.

17. Kadi MR, Hepgüler S, Atamaz FC, Dede E, Aydogdu S, Aktuglu K, et al. Is interferential current effective in the management of pain, range of motion, and edema following total knee arthroplasty surgery? A randomized double-blind controlled trial. Clin Rehabil. 2019; Epub ahead.

18. Nazligul T, Akpinar P, Aktas I, Ozkan FU, Hartevioglu HC. The effect of interferential current therapy on patients with subacromial impingement syndrome:a randomized, double-blind, sham-controlled study. Eur J Phys Rehabil Med. 2018; 54(3): 351-7.

19. Lara-Palomo IC, Aguilar-Ferrándiz ME, Matarán-Peñarrocha GA, Saavedra-Hernández M, Granero-Molina J, Fernández-Sola C, et al. Short-term effects of interferential current electro- massage in adults with chronic non-specific low back pain: a randomized controlled trial. Clin Rehabil. 2012; 27(5): 439-49.

20. Franco YRS, Franco KFM, Silva LA, Silva MO, Rodrigues MN, Liebano $\mathrm{RE}$, et al. Does the use of interferential current prior to pilates exercises accelerate improvement of chronic nonspecific low back pain? Pain Manag. 2018; 8(6): 465-74.

21. Franco KM, Franco Y dos S, Oliveira NB de, Miyamoto GC, Santos MO, Liebano RE, et al. Is interferential current before Pilates exercises more effective than placebo in patients with chronic nonspecific low back pain?: A randomized controlled trial. Arch Phys Med Rehabil. 2017; 98(2): 320-8.

22. Hurley DA, McDonough SM, Dempster M, Moore AP, Baxter GD. A randomized clinical trial of manipulative therapy and interferential therapy for acute low back pain. Spine (Phila Pa 1976). 2004; 29(20): 2207-16.

23. Venancio RC, Pelegrini S, Gomes Q, Nakano EY, Liebano E. Effects of carrier frequency of interferential current on pressure pain threshold and sensory comfort in humans. Arch Phys Med Rehabil. 2013; 94(1): 95-102.

24. Palmer ST, Martin DJ, Steedman WM, Ravey J, St AP, Dj M, et al. Alteration of interferential current and transcutaneous electrical nerve stimulation frequency: effects on nerve excitation. Arch Phys Med Rehabil. 1999; 80(9): 1065-71.

25. Beatti A, Rayner A, Chipchase L, Souvlis T. Penetration and spread of interferential current in cutaneous, subcutaneous and muscle tissues. Physiotherapy. 2011; 97(4): 319-26.

26. Fiori A, Cescon CLC, Galesky JDF, Santos TACD, Brancalhaõ RMC, Bertolini GRF. Comparison between bipolar and tetrapolar of the interferential current in nociceptive threshold, accommodation and pleasantness in healthy individuals. Eur J Physiother. 2014; 16(4): 201-5. 